\title{
Pseudoacromegaly in pachydermoperiostosis
}

\author{
Partha Pratim Chakraborty, ${ }^{1}$ Rana Bhattacharjee, ${ }^{2}$ Satinath Mukhopadhyay, ${ }^{2}$ \\ Subhankar Chowdhury ${ }^{2}$
}

${ }^{1}$ Department of Medicine, Midnapore Medical College \& Hospital, Midnapore, West Bengal, India

${ }^{2}$ Department of Endocrinology \& Metabolism, Institute of Postgraduate Medical

Education and Research/SSKM Hospital, Kolkata, West Bengal, India

\section{Correspondence to} Dr Partha Pratim Chakraborty, docparthapc@yahoo.co.in

Accepted 3 February 2016
CrossMark

To cite: Chakraborty PP Bhattacharjee $\mathrm{R}$,

Mukhopadhyay S, et al. BMJ Case Rep Published online: [please include Day Month Year] doi:10.1136/bcr-2016214624

\section{DESCRIPTION}

A 19-year-old male patient presented with a yearlong history of progressive painful enlargement of his hands and feet associated with excessive sweating and greasiness of the face, palms and soles. $\mathrm{He}$ also noticed pain over his wrists and ankles without any symptoms suggestive of raised intracranial tension and no recent increase in height. Family history was unremarkable. Clinical examination revealed enlargement of hands and feet with digital clubbing and spade-like appearance of the hands (figures 1 and 2). The eyelids were hypertrophied with partial drooping of the upper eyelids. The skin over the patient's face and extremities was coarse, moist and oily, suggestive of excessive sebum secretion. He had no prognathism and no obvious furrowing of skin over face or scalp. Systemic examination was unremarkable.

Baseline investigations were normal. A detailed hormonal evaluation including the growth hormone $(\mathrm{GH})$ insulin-like growth factor 1 (IGF1) axis, thyroid functions, and fasting and postmeal serum insulin levels, were within reference range. Radiographs of the hands, feet and long bones revealed subperiosteal new bone formation with irregular outline of the cortical surfaces of the phalanges, metacarpals and long bones (figure 3 ). The heel pad thickness on lateral foot X-ray was $19 \mathrm{~mm}$ (normal $<21 \mathrm{~mm}$ ) (figure 4). A thorough search for underlying heart disease, or a neoplastic or infectious process, with chest X-ray, echocardiography, CT of the thorax and abdomen, barium studies and upper and lower gastrointestinal endoscopies being negative, was unsuccessful.

The patient was initially put on oral nonsteroidal anti-inflammatory drugs (NSAID) for pain relief. However, because of poor response to the NSAIDs, intravenous zoledronic acid was added, after which he noticed significant subjective

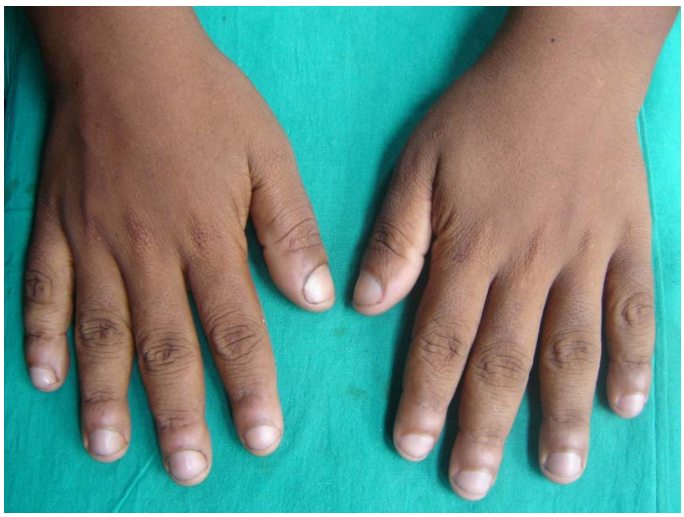

Figure 1 Enlarged spade-shaped hands with digital clubbing.

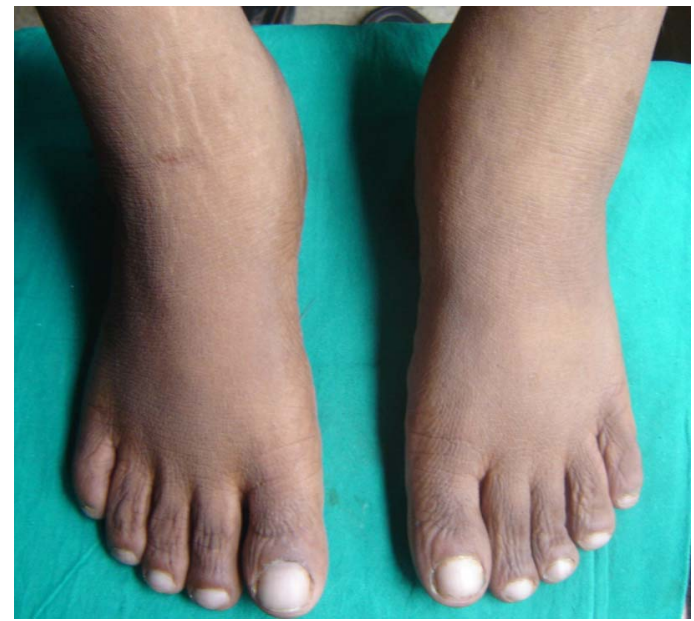

Figure 2 Enlarged feet with swollen ankles.

improvement about 1 week after a single $5 \mathrm{mg}$ infusion. Although we did not notice definite radiological regression of the periostitis after 3 months, keeping in mind the patient's symptomatic relief, repeat administration of zoledronic acid at yearly intervals has been planned.

Acromegaly is characterised by soft tissue and bony overgrowth due to increased activity of the GH-IGF1 axis. Patients with physical appearance mimicking acromegaly but with an intact somatotroph axis are said to have pseudoacromegaly. Pachydermoperiostosis, also known as primary hypertrophic osteoarthropathy, or TouraineSolente-Golé syndrome, is a rare syndrome characterised by subperiosteal new bone formation, digital clubbing, coarsening of facial features with thickening, furrowing and oiliness of the facial skin, and a resultant acromegaloid appearance. In

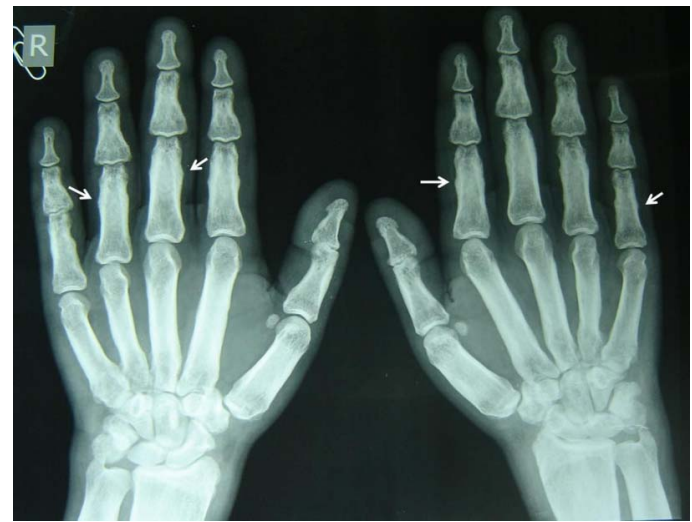

Figure 3 X-ray of the hands showing irregular cortical surfaces of phalanges and metacarpals due to subperiosteal new bone formation (white arrows). 


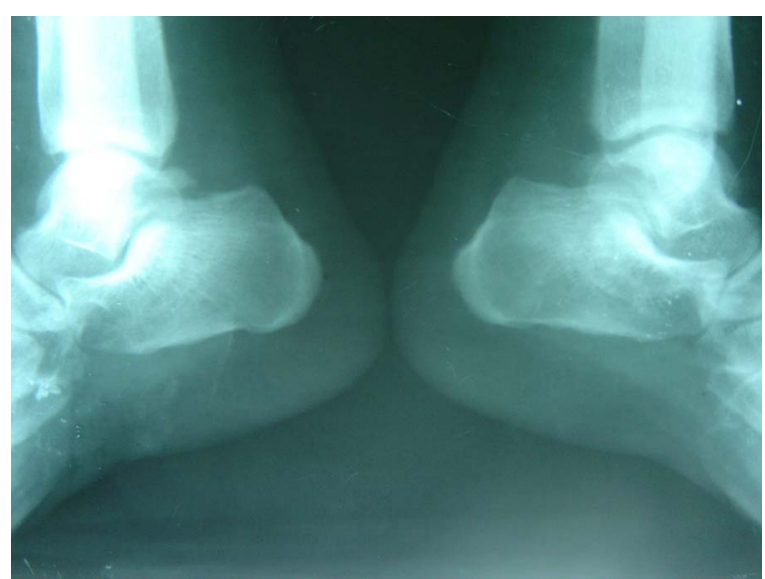

Figure 4 Lateral $\mathrm{X}$-ray of the feet shows normal heel pad thickness $(19 \mathrm{~mm})$.

severe cases, when the furrowing involves the scalp, with an undulating grooved appearance, it is called cutis verticis gyrata. ${ }^{1}$

Pachydermoperiostosis, though commonly presenting sporadically, may be inherited in an autosomal dominant fashion or as an $\mathrm{X}$ linked trait. This self-remitting disorder usually involves peri-pubertal young males and in a classic case, disease progression stops at the end of adolescence and the disease usually stabilises after 5-20 years of onset. Systemic proinflammatory cytokines and enhanced bone remodelling have been postulated to play the aetiological role; however, the exact pathogenesis is largely unknown.

The clinical diagnosis is confirmed with the help of a typical radiological appearance of subperiosteal new bone formation and only after excluding hypersomatotropism and the different causes of secondary hypertrophic osteoarthropathy, underlying malignancy in particular. ${ }^{2} 3$

Usual treatment includes NSAID and, occasionally, systemic glucocorticoids for pain relief. Osteoclastic activity has an intimate relationship with the local cytokine network and pachydermoperiostosis is associated with an increased number of osteoclasts in bone and a high level of IL-6. Bisphosphonates are pyrophosphate analogues that preferentially bind to the mineral phase of bone, enter the osteoclasts, rapidly inhibit resorption by blocking the enzyme farnesyl diphosphate synthase in the 3-hydroxy-3-methylglutaryl-coenzyme A (HMG$\mathrm{CoA})$ reductase pathway and thus reduce bone remodelling. The rationale of bisphosphonate use to alleviate pain is in their antiresorptive and anti-inflammatory effects.

\section{Learning points}

- Pachydermoperiostosis is a close differential diagnosis of acromegaly and pulmonary hypertrophic osteoarthropathy.

- A normal growth hormone-insulin-like growth factor 1 axis, characteristic radiological appearances and a negative work up for underlying malignancy, clinch the diagnosis.

- Typical X-ray findings of acromegaly, such as 'ballooned' pituitary fossa, enlarged frontal sinuses, 'tufting' of tips of terminal phalanges, prominent marginal osteophytes over small bones and vertebrae, widened joint spaces and 'wasting' of metatarsal and proximal phalangeal shafts are absent in pachydermoperiostosis.

- The disease commonly involves peripubertal males, and is self-limiting and treated symptomatically.

Contributors PPC and RB were involved in diagnosis, management, manuscript writing and literature review. SM and SC were involved in diagnosis, management and finalising of the manuscript.

Competing interests None declared.

\section{Patient consent Obtained.}

Provenance and peer review Not commissioned; externally peer reviewed.

\section{REFERENCES}

1 Rimoin DL. Pachydermoperiostosis (idiopathic clubbing and periostosis): genetic and physiologic considerations. N Engl J Med 1965;272:923-31.

2 Singh GR, Menon PS. Pachydermoperiostosis in a 13-year-old boy presenting as an acromegaly-like syndrome. J Pediatr Endocrinol Metab 1995;8:51-4.

3 Bhansali $A$, Singh $R$, Sriraam M, et al. Pachydermoperiostitis and bisphosphonates. J Assoc Physicians India 2006;54:340

Copyright 2016 BMJ Publishing Group. All rights reserved. For permission to reuse any of this content visit

http://group.bmj.com/group/rights-licensing/permissions.

BMJ Case Report Fellows may re-use this article for personal use and teaching without any further permission.

Become a Fellow of BMJ Case Reports today and you can:

- Submit as many cases as you like

- Enjoy fast sympathetic peer review and rapid publication of accepted articles

- Access all the published articles

- Re-use any of the published material for personal use and teaching without further permission

For information on Institutional Fellowships contact consortiasales@bmjgroup.com

Visit casereports.bmj.com for more articles like this and to become a Fellow 